\title{
Butyrivibrio hungatei sp. nov. and Pseudobutyrivibrio xylanivorans sp. nov., butyrate- producing bacteria from the rumen
}

\author{
Jan Kopečný, ${ }^{1}$ Maša Zorec, ${ }^{2}$ Jakub Mrázek, ${ }^{1}$ Yasuo Kobayashi ${ }^{3}$ \\ and Romana Marinšek-Logar ${ }^{2}$ \\ ${ }^{1}$ Institute of Animal Physiology and Genetics, Czech Academy of Sciences, Prátelství 560, \\ 104 00, Prague 10, Uhř́něves, Czech Republic \\ ${ }^{2}$ University of Ljubljana, Biotechnical Faculty, Zootechnical Dept, Domžale, Slovenia \\ ${ }^{3}$ Hokkaido University, Graduate School of Agriculture, Sapporo 060-8589, Japan
}

Correspondence Jan Kopečný kopecny@iapg.cas.cz
Two novel Gram-negative, anaerobic, non-spore-forming, butyrate-producing bacterial species, strains $\mathrm{Mz} 5^{\top}$ and $\mathrm{JK} 615^{\top}$, were isolated from the rumen fluid of cow and sheep. Both strains were curved rods that were motile by means of single polar or subpolar flagellum and common in the rumen microbial ecosystem. Strain $\mathrm{Mz} 5^{\top}$ produced high xylanase, proteinase, pectin hydrolase and DNase activities; $1,4-\beta$-endoglucanase was also detected in the culture medium. The bacterium utilized a wide range of carbohydrates. Glucose was fermented to formate, butyrate, lactate, succinate and ethanol. The DNA G $+\mathrm{C}$ content was $42 \cdot 1 \mathrm{~mol} \%$. The complete $16 \mathrm{~S}$ rDNA sequence was obtained and phylogenetic relationships were determined. Strain $\mathrm{Mz} 5^{\top}$ and related isolates were located in clostridial cluster XIVa and were closely related to Pseudobutyrivibrio ruminis, Butyrivibrio crossotus, Roseburia cecicola and Eubacterium rectale. The name proposed for this novel bacterium is Pseudobutyrivibrio xylanivorans; the type strain is $\mathrm{Mz} 5^{\top}$

$\left(=\mathrm{DSM} 14809^{\top}=\right.$ ATCC BAA $\left.-455^{\top}\right)$. Strain JK $615^{\top}$ produced no fibrolytic activity, but utilized a wide range of carbohydrates. Glucose was fermented to formate, acetate, butyrate and ethanol. The DNA G + C content was 44.8 mol\%. The complete $16 \mathrm{~S}$ rDNA sequence was obtained and phylogenetic relationships were determined. Strain JK $615^{\top}$ was located in clostridial cluster XIVa and was closely related to Clostridium proteoclasticum, Butyrivibrio fibrisolvens and Eubacterium halii. The name proposed for this novel bacterium is Butyrivibrio hungatei; the type strain is $\mathrm{JK} 615^{\top}$ $\left(=\operatorname{DSM} 14810^{\top}=\right.$ ATCC BAA $\left.-456^{\top}\right)$.

\section{INTRODUCTION}

Butyrivibrio isolates represent a significant proportion (10-30\%) of culturable rumen bacteria in domestic and wild ruminants (Forster et al., 1996, 1997; Stewart et al., 1997) and have been observed in DNA samples of uncultivated rumen bacteria (Tajima et al., 1999). A large number of Butyrivibrio strains contributes to fibre degradation in the rumen. Most isolates synthesize xylanase, amylase and cellodextrinase, but few strains produce 1,4- $\beta$-endoglucanase (Stewart et al., 1997). Butyrivibrio isolates are usually able to utilize a wide spectrum of sugar monomers and oligomers.

Published online ahead of print on 9 August 2002 as DOI 10.1099/ ijs.0.02345-0.

The EMBL accession numbers for the 16S rDNA sequences of Pseudobutyrivibrio xylanivorans $\mathrm{Mz} 5^{\top}$, Pseudobutyrivibrio ruminis JK 626, Pseudobutyrivibrio xylanivorans JK 23/2, Pseudobutyrivibrio xylanivorans JK 633, Clostridium proteoclasticum UC 142 and Butyrivibrio hungatei JK $615^{\top}$ are AJ428548-AJ428553, respectively.
Up to now, most butyrate-producing isolates have been assigned to Butyrivibrio fibrisolvens on the basis of common phenotypic and metabolic characteristics, despite their vast diversity and genetic unrelatedness. Great variation between B. fibrisolvens strains has been observed in reactions with polyclonal (Margherita et al., 1964) and monoclonal (Hazlewood et al., 1986) antibodies, fermentation products and utilization of sugars (Diez-Gonzalez et al., 1999; Van der Toorn \& Van Gylswyk, 1985), cell-wall composition (Hespell et al., 1993), sugar composition of extracellular polysaccharides (Stack, 1988), and DNA-DNA hybridization (Hudman \& Gregg, 1989; Mannarelli et al., 1990). 16S rDNA sequencing has confirmed the vast genetic heterogeneity of and great phylogenetic distances between different isolates in the Butyrivibrio group (Forster et al., 1996; Willems et al., 1996; Kopečný et al., 2001). Similar variations have been observed in butyrate-producing bacteria from the human gut (Barcenilla et al., 2000).

Recently, three species have been described that are 
genetically related to B. fibrisolvens: lophotrichous Butyrivibrio crossotus from the human gut (Moore et al., 1976); proteolytic Clostridium proteoclasticum (Attwood et al., 1996); and lactate-producing Pseudobutyrivibrio ruminis (Van Gylswyk et al., 1996) from the rumen. Descriptions of these species have significantly improved the taxonomy of butyrate-producing anaerobic bacteria from the digestive tract.

The aim of this study was to collect taxonomic data for the possible classification of novel species of butyrateproducing anaerobic bacteria from the animal digestive tract.

\section{METHODS}

Strains and culture conditions. Butyrate-producing strains were isolated from rumen fluid and faeces of domestic ruminants. Isolations were done under anaerobic conditions in medium M10 with $10 \%$ rumen fluid containing glucose or cellobiose $\left(4 \mathrm{~g} \mathrm{l}^{-1}\right)$ as a growth substrate. Reference strains were obtained from different culture collections (Table 1). We greatly appreciate the gifts of G. T. Attwood (Palmerston, New Zealand), K. Gregg (Perth, WA, Australia), N. O. van Gylswyk (Uppsala, Sweden) and C. S. Stewart (Aberdeen, UK). Bacterial cultures were kept in $15 \%(\mathrm{v} / \mathrm{v})$ glycerol at $-70^{\circ} \mathrm{C}$. For further analyses, strains were grown in medium M10 with $10 \%$ rumen fluid and $4 \mathrm{~g}$ cellobiose $\mathrm{l}^{-1}$ (Kopečný et al., 2001) or in DSM medium no. 330 without rumen fluid.

Analyses of fermentation products. Short-chain fatty acids, ethanol, succinate and lactate were analysed by GLC following double ether extraction or methylation of culture supernatants (Holdeman et al., 1977) on a Shimadzu GC-14A chromatograph equipped with an FID detector and Supelcowax 10 capillary column (Supelco).

Substrate utilization and degradation of biopolymers. Substrate utilization and enzyme activities were tested with kits for anaerobic bacteria: API 20 and ID 32 (bioMérieux). Separate analyses were carried out on extracellular activities of amylase, xylanase, laminarinase (1,3- $\beta$-glucanase), proteinase, pectin hydrolase and DNase (Kopečný \& Bartoš, 1990; Avguštin et al., 1997).

GC determination of cellular fatty acid composition. Cells cultured in DSM medium no. 330 without rumen fluid were harvested by centrifugation at 3000 r.p.m. at $4{ }^{\circ} \mathrm{C}$ for $10 \mathrm{~min}$. Pellets were washed twice in sodium phosphate buffer $(50 \mathrm{mM}, \mathrm{pH} 6 \cdot 5)$. Preparation of fatty acid methyl esters by saponification, methylation and extraction into hexane and sample clean-up were done following the procedure of Moore et al. (1994). Methyl esters were analysed on an HP fused silica capillary column Ultra2 (HP 19091B102) using a Shimadzu GC-14 A chromatograph equipped with an FID detector and Chromatopac C-R6A for data processing. A calibration standard kit (fatty acid methyl esters in hexane, HP 1929860500) was used for identification of fatty acids and equivalent chain length factors were calculated for unknown peaks (Moore et al., 1994). Relative concentrations of individual fatty acids were calculated as percentages. Bacterial strains were grouped according to the similarity of their cellular fatty acid profiles.

Transmission electron microscopy. Bacterial colonies were resuspended in filtered water, transferred onto grids covered with Formvar support film (Robards \& Wilson, 1993) and negatively stained with an equal volume of $0.5 \%(\mathrm{w} / \mathrm{v})$ aqueous uranyl acetate (Robards \& Wilson, 1993). Stained bacteria were air-dried at room temperature and examined with a Philips CM 100 EM. The images were recorded by a Gatan Bioscan CCD camera using DIGITALMICROGRAPH software.

RFLP analyses. DNA of selected strains was isolated (Gregg et al., 1994) and 16S rDNA regions (1490 bp) were amplified by PCR with the aid of primers $\mathrm{fD} 1$ and rP2 (Weisburg et al., 1991; Barcenilla et al., 2000). Obtained fragments were digested at $37^{\circ} \mathrm{C}$ for $2 \mathrm{~h}$ with restriction endonucleases $\mathrm{HaeIII}$ and $A l u \mathrm{I}$ and then analysed by electrophoresis in $2 \%$ agarose gels (Sambrook et al., 1989).

DNA sequencing and phylogenetic tree construction. 16S rDNA fragments were obtained after amplifying $500 \mathrm{bp}$ regions of bacterial DNA with primers FP27/515R, FP3/RP16 and FP19/rP2 (Forster et al., 1996) on a thermocycler. These fragments were sequenced with an ABI 310 capillary sequencer (Perkin-Elmer). After editing, full $16 \mathrm{~S}$ rDNA sequences were compared with published sequences of related bacteria from the EMBL and GenBank nucleotide databases using BLAST and with data from the Ribosomal Database Project (Maidak et al., 1994). The sequences were aligned using CLUSTAL W (Thompson et al., 1994) in the BIOEDIT program (Hall, 1999) and a phylogenetic tree was generated with the PHYLIP package (Felsenstein, 1989). Sequence data for distance matrices and analysis were subjected to bootstrap resampling (resampled 1000 times) using the SEQBOOT program. The DNADIST program analysed distances using the Kimura-Nei correction (Kimura, 1980) trees produced from distance matrices that used the neighbourjoining method (Saitou \& Nei, 1987). A consensus tree was generated by the CONSENSE program (Felsenstein, 1985).

DNA G + C content. Estimation of the $\mathrm{G}+\mathrm{C}$ contents in bacterial chromosomal DNAs was done after extraction and enzymic hydrolysis by HPLC on a C18 reversed-phase column (Supelcosil LC18; Supelco) with the same guard column (Mesbah et al., 1989). DNAs from Escherichia coli strain B $(50 \mathrm{~mol} \%)$ and calf thymus (42 mol\%) were used as reference samples for $\mathrm{G}+\mathrm{C}$ content.

Genera-specific PCR. Specific forward PCR primers developed previously for the genera Butyrivibrio (71f; 5'-CGG AGA ATT TAC GCT GAT GAA G) and Pseudobutyrivibrio (F2; 5'-AAT TTT CTA CGA TCC CTT CGG GG) were used with reverse primer 515R (Mrázek \& Kopečný, 2001) to distinguish both genera.

\section{RESULTS AND DISCUSSION}

\section{Genotypic variations}

The high genetic diversity of Butyrivibrio isolates has been proven many times (Hudman \& Gregg, 1989; Willems et al., 1996; Forster et al., 1996). To characterize our isolates, RFLP analysis (with restriction endonucleases AluI and HaeIII) of the 16S rDNA fragments from 42 Butyrivibrio isolates (Table 1), obtained from the digestive tract of ruminants, was used. According to variable fragment size in fingerprints, restriction patterns isolates clustered into five groups. Three of these groups corresponded with three previously described species: B. fibrisolvens, $P$. ruminis and C. proteoclasticum. Two other homogeneous groups of bacteria with different restriction profiles were observed (Table 2).

Representatives of each group (JK $615^{\mathrm{T}}$, UC 142, JK 626, $\mathrm{Mz} 5^{\mathrm{T}}$, JK 23/2 and JK 633) were selected and fragments of $1500 \mathrm{nt}$ encoding the $5^{\prime}$ end of the 16S DNA were 
Table 1. Strains of Butyrivibrio used in the present study, their origin and DNA $G+C$ content

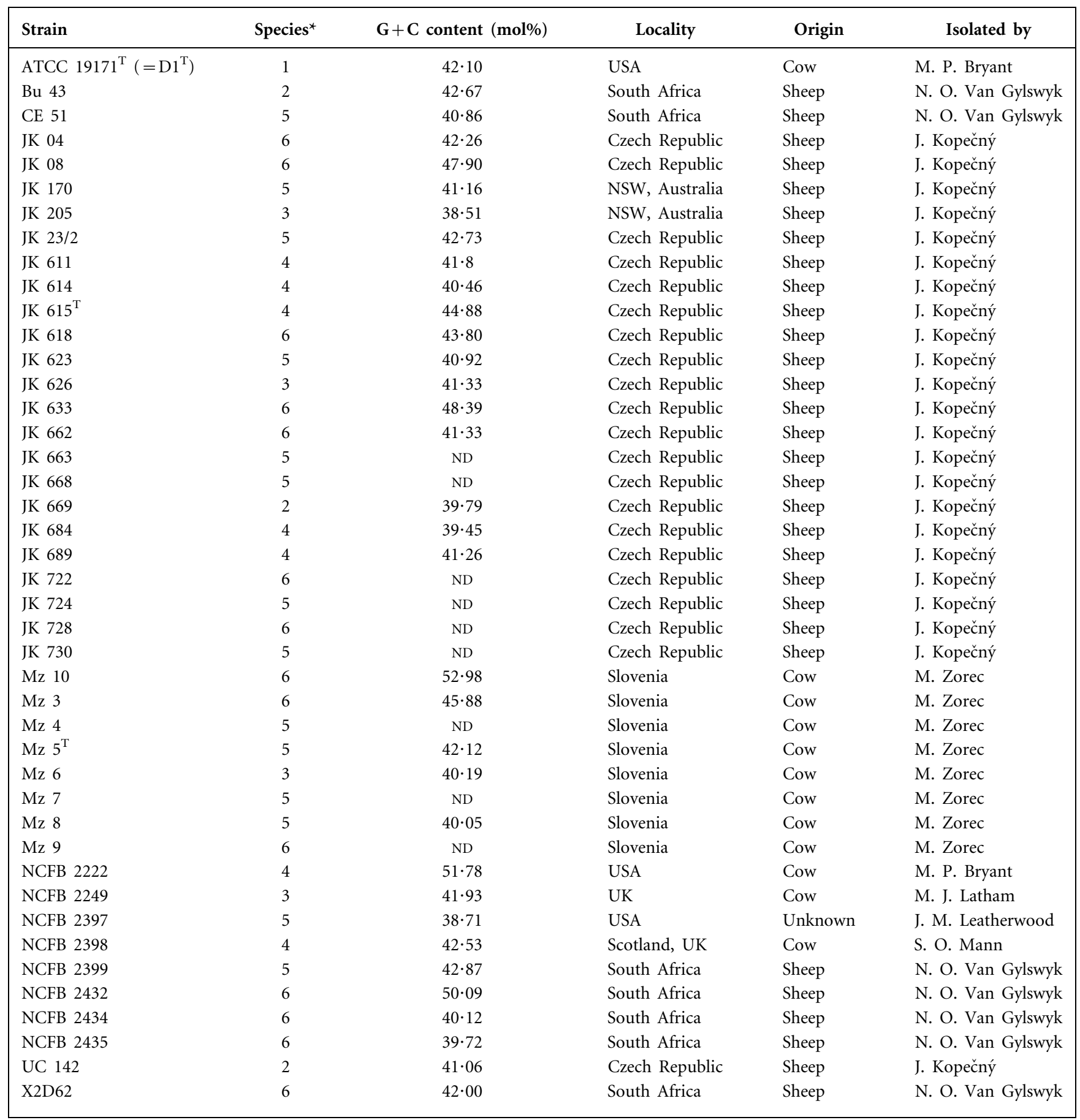

ND, Not determined.

${ }^{\star}$ Numbers refer to the following species: 1, B. fibrisolvens; 2, C. proteoclasticum; 3, P. ruminis; 4, B. hungatei; 5, P. xylanivorans; 6, Butyrivibrio spp.

sequenced. Neighbour-joining analysis of a distance matrix obtained from a multiple-sequence alignment resulted in an unrooted phylogenetic tree of selected strains with Clostridium oroticum as an outgroup (Fig. 1). All strains tested were located in the XIVa cluster of the Grampositive bacteria (Collins et al., 1994). For two groups of isolates, the assignment of two novel species, Butyrivibrio hungatei and Pseudobutyrivibrio xylanivorans, is proposed. The proposed novel species were significantly different from previously described species. All Butyrivibrio isolates formed two large groups.

The first group included isolates related to the type strain, $\mathrm{D} 1^{\mathrm{T}}$, of B. fibrisolvens, a cluster of C. proteoclasticum and 
Table 2. RFLPs obtained with $A / u$ l and Haell with $16 \mathrm{~S}$ rDNA fragments from Butyrivibrio isolates

\begin{tabular}{|c|c|c|c|}
\hline Group of isolates ${ }^{\star}$ & $n \dagger$ & $\begin{array}{c}\text { Restriction } \\
\text { endonuclease }\end{array}$ & $\begin{array}{l}\text { Fragment } \\
\text { size (bp) }\end{array}$ \\
\hline \multirow[t]{2}{*}{ B. fibrisolvens } & 2 & AluI & 950,420 \\
\hline & & HaeIII & 560,270 \\
\hline \multirow[t]{2}{*}{ P. ruminis } & 8 & AluI & $445,420,220$ \\
\hline & & HaeIII & $1100,270,200$ \\
\hline \multirow[t]{2}{*}{ C. proteoclasticum } & 7 & AluI & 950,380 \\
\hline & & HaeIII & 300,250 \\
\hline \multirow[t]{2}{*}{ B. hungatei } & 8 & $A l u \mathrm{I}$ & 570,300 \\
\hline & & HaeIII & $900,300,250$ \\
\hline \multirow[t]{2}{*}{ P. xylanivorans } & 17 & $A l u \mathrm{I}$ & $880,420,220$ \\
\hline & & HaeIII & $1100,320,270$ \\
\hline
\end{tabular}

${ }^{\star} B$. fibrisolvens strains were $\mathrm{D} 1^{\mathrm{T}}$ and Mz10. P. ruminis strains were NCFB 2249, JK 08, JK 205, JK 618, JK 626, JK 662, JK 728 and Mz 6. C. proteoclasticum strains were NCFB 2432, NCFB 2435, Bu 43, JK 669, JK 722, UC 142 and X2D62. B. hungatei strains were NCFB 2398, NCFB 2434, JK 611, JK 614, JK 615 ${ }^{\mathrm{T}}$, JK 684, JK 689 and Mz 9. P. xylanivorans strains were CE 51, NCFB 2397, NCFB 2399, JK 04, JK 23/2, JK 170, JK 623, JK 633, JK 663, JK 668, JK 724, JK 730, Mz $3, \mathrm{Mz} 4, \mathrm{Mz}^{\mathrm{T}}, \mathrm{Mz} 7$ and $\mathrm{Mz} 8$.

†Number of strains representing each species.

a cluster of $B$. hungatei. These two clusters were closely related to $B$. crossotus. The second group included two clusters containing P. ruminis and P. xylanivorans, respectively. Both groups were related to butyrate-producing bacteria from the human colon (UnId L1-83, L1-810 and T1-815), which were similar to Roseburia cecicola and Eubacterium rectale.

16S rDNA sequence similarities of $B$. hungatei with B. fibrisolvens $(93.7 \%)$, C. proteoclasticum $(95 \cdot 7 \%)$ and B. crossotus $(90 \cdot 6 \%)$ were estimated. Similarly, sequence similarities of $P$. xylanivorans with $P$. ruminis $(96.4 \%)$, B. fibrisolvens $(89 \cdot 5 \%)$ and $B$. crossotus $(89 \cdot 6 \%)$ were also determined.

DNA $G+C$ content data are summarized in Table 3 . The mean values for most isolates are in the range 40-44 mol\%. This range is in agreement with values described for the genera Butyrivibrio and Pseudobutyrivibrio (Stewart et al., 1997; Van Gylswyk et al., 1996). The G+C content data of novel strains resembling $C$. proteoclasticum were in the same range, contrary to the published value $(28 \mathrm{~mol} \%)$ for the type strain of $C$. proteoclasticum, which was significantly lower (Attwood et al., 1996). The mean values for $\mathrm{G}+\mathrm{C}$ contents of the novel species were $41.6 \mathrm{~mol} \%$ for B. hungatei and $42 \cdot 7 \mathrm{~mol} \%$ for $P$. xylanivorans.

\section{Fermentation end products}

All strains under analysis fermented glucose to butyrate, hydrogen, ethanol, carbon dioxide and formate. Isolates

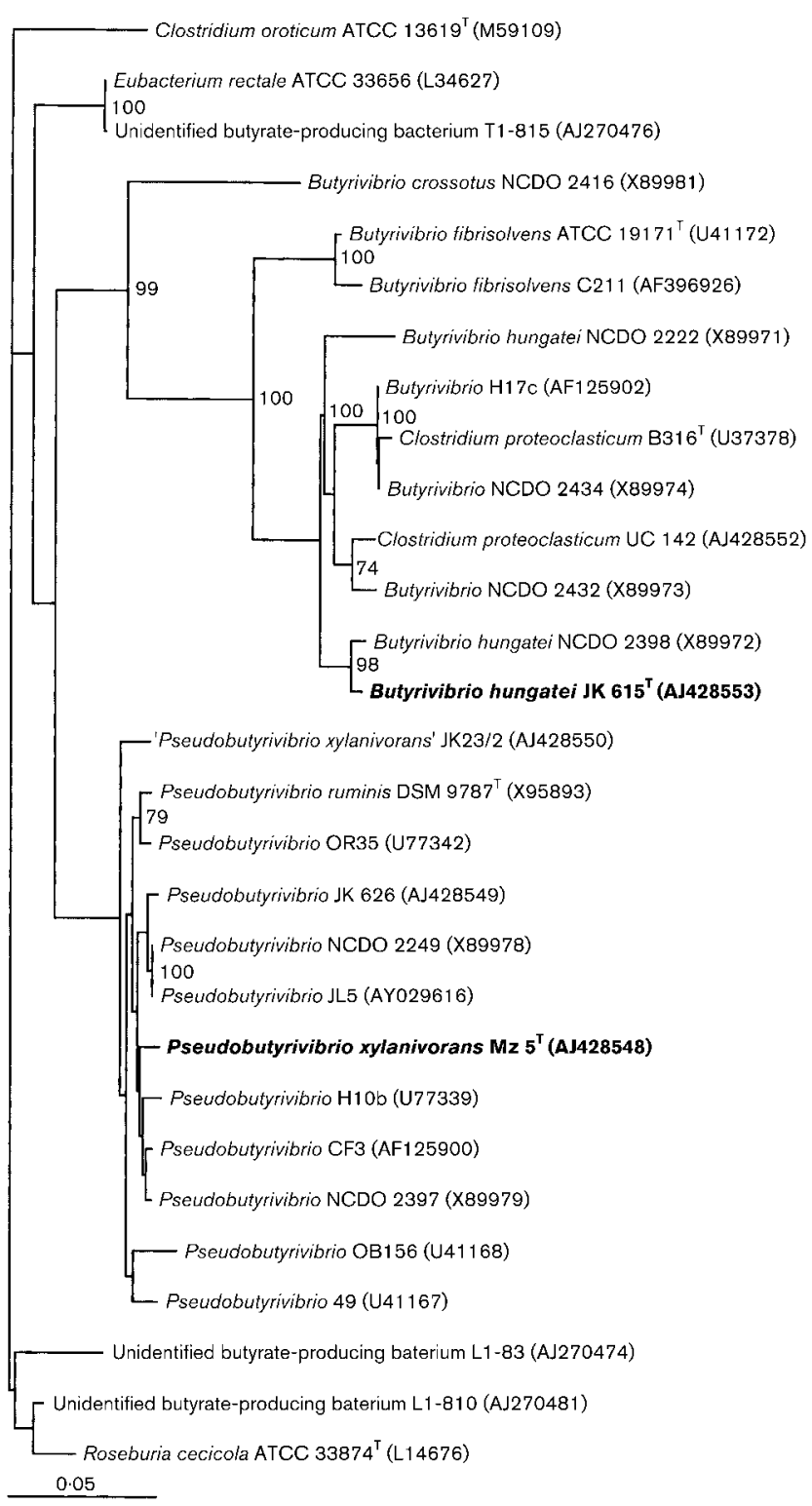

Fig. 1. Phylogenetic tree showing relationships of $16 \mathrm{~S}$ rDNA sequences of different isolates of Butyrivibrio. Bar, 5 substitutions per 100 nt. The tree was constructed using neighbour-joining analysis of a distance matrix obtained from a multiple-sequence alignment. Clostridium oroticum was used as an outgroup sequence.

producing lactate were mainly $P$. ruminis strains. In fact, lactate production is one of the main characteristics for the identification of P. ruminis (Van Gylswyk et al., 1996). High production of lactate by Butyrivibrio isolates was connected with the presence of butyryl-CoA/acetate CoA transferase (Diez-Gonzalez et al., 1999). In agreement with that, in our $P$. ruminis strains, lactate production was associated with acetate utilization. Roche et al. (1973) described these isolates as acetate-utilizing butyrivibrios. Lactate was also produced by $B$. fibrisolvens $\mathrm{D} 1^{\mathrm{T}}$. 
Table 3. Some characteristics that distinguish different butyrate-producing bacteria from the digestive tract of ruminants

Species: 1, B. fibrisolvens (strain D1 ${ }^{\mathrm{T}}$ ); 2, P. ruminis (strains NCFB 2249, JK 205, JK 626 and Mz 6); 3, C. proteoclasticum (strains Bu 43, JK 669 and UC 142); 4, B. hungatei (strains NCFB 2398, NCFB 2434, JK 611, JK 614, JK 615 ${ }^{\mathrm{T}}$, JK 684, JK 689 and Mz 9); 5, P. xylanivorans (strains CE 51, NCFB 2397, NCFB 2399, JK 04, JK 23/2, JK 170, JK 623, JK 633, JK 663, JK 668, JK 724, JK 730, Mz 3, Mz 4, Mz 5², Mz 7 and $\mathrm{Mz} 8$ ). With the exception of DNA G+C content, results are expressed as percentage of positive results.

\begin{tabular}{|c|c|c|c|c|c|}
\hline Characteristic & 1 & 2 & 3 & 4 & 5 \\
\hline DNA G $+\mathrm{C}$ content $(\mathrm{mol} \%)^{*}$ & $41 \cdot 2(1)$ & $41 \cdot 1 \pm 1 \cdot 3(4)$ & $40 \cdot 2 \pm 0 \cdot 6(3)$ & $41 \cdot 6 \pm 1 \cdot 1(6)$ & $42 \cdot 7 \pm 1 \cdot 4(14)$ \\
\hline \multicolumn{6}{|l|}{ Hydrolase activity: } \\
\hline Xylanase & 100 & 0 & 33 & 33 & 100 \\
\hline Proteinase & 0 & 0 & 100 & 0 & 86 \\
\hline Carboxymethyl cellulase & 100 & 25 & 0 & 0 & 43 \\
\hline Pectinase & 0 & 0 & 67 & 17 & 36 \\
\hline \multicolumn{6}{|l|}{ Fermentation products: } \\
\hline Acetate production & 0 & 0 & 100 & 100 & 0 \\
\hline Lactate production & 100 & 100 & 0 & 0 & 10 \\
\hline Leucyl-glycine arylamidase & 100 & 0 & 0 & 0 & 21 \\
\hline Histidine arylamidase & 100 & 0 & 0 & 33 & 29 \\
\hline$\alpha$-Fucosidase & 100 & 0 & 100 & 67 & 7 \\
\hline Glycine arylamidase & 100 & 0 & 0 & 17 & 29 \\
\hline \multicolumn{6}{|l|}{ PCR primers $\dagger$} \\
\hline Pseudobutyrivibrio & 0 & 100 & 0 & 0 & 100 \\
\hline Butyrivibrio & 100 & 0 & 100 & 100 & 0 \\
\hline
\end{tabular}

*The numbers in parentheses refer to the numbers of strains examined.

†See Mrázek \& Kopečný (2001).

Isolates of $C$. proteoclasticum and B. hungatei did not produce lactate at all or did so in small quantities (less than $\left.0.5 \mathrm{mmol} \mathrm{l}^{-1}\right)$. Production of acetate was observed in most cultures of $C$. proteoclasticum and B. hungatei. Ethanol was produced by most strains of $P$. xylanivorans and B. hungatei.

Hungate (1966) preliminarily classified isolates producing butyrate and acetate but not producing lactate and ethanol as 'Butyrivibrio alactacidigens'.

\section{Substrate utilization}

The substrate utilization of our 42 Butyrivibrio and Pseudobutyrivibrio strains was tested with API 20A test kits. No strains produced catalase or indole. All strains used glucose, cellobiose, maltose and aesculin. Only strains JK 633 and JK 730 did not use sucrose and mannose. Results obtained with all other substrates tested were variable. These facts are in agreement with previous attempts to reclassify Butyrivibrio isolates (Hungate, 1966; Hudman \& Gregg, 1989).

\section{Polysaccharidase activities}

Amylase production was observed in many Butyrivibrio isolates (McAllister et al., 1990). This activity was characteristic for most of the P.xylanivorans isolates (Table 3). Other existing and proposed species did not produce any significant amylase activity at all. Xylanase activity was typical of B. fibrisolvens $\mathrm{D} 1^{\mathrm{T}}$ and isolates of P. xylanivorans. $P$. ruminis did not produce any xylanase activity. In C. proteoclasticum and B. hungatei, the xylanase activity varied (Table 3). Laminarinase activity was observed in several isolates of $C$. proteoclasticum, B. hungatei and P. xylanivorans only; B. fibrisolvens and P. ruminis isolates did not produce this enzyme activity at all.

$\beta$-Endoglucanase was characteristic of $B$. fibrisolvens $\mathrm{D} 1^{\mathrm{T}}$ and several isolates of $P$. ruminis and P. xylanivorans. No activity was observed in strains of $C$. proteoclasticum and $B$. hungatei. Pectin hydrolase was not produced by strains of B. fibrisolvens, P. ruminis or B. hungatei. In the rest of the tested species, the activity differed. The presence of pectin hydrolase was observed only in C. proteoclasticum 
isolates. Activity of $\alpha$-fucosidase was characteristic of B. fibrisolvens $\mathrm{D} 1^{\mathrm{T}}$ and C. proteoclasticum. $\alpha$-Fucosidase was not detected in $P$. ruminis or in most of the $P$. xylanivorans isolates. $\alpha$-Fucosidase activity was not observed in all isolates of $B$. hungatei.

\section{Proteinase and peptidase activities}

It has been accepted that Butyrivibrio strains have an important role in protein degradation in the rumen (Attwood \& Reilly, 1995). Proteinase activity (Table 3) was characteristic for all strains of C. proteoclasticum and most isolates (12 out of 14 strains tested) of P. xylanivorans. Azocasein was not hydrolysed by all strains of $B$. hungatei, $P$. ruminis or $B$. fibrisolvens $\mathrm{D} 1^{\mathrm{T}}$. The distribution of proteolytic activity estimated with azocasein did not fully correlate with the gelatin hydrolysing activity observed in API 20 tests. Glycine arylamidase and leucyl-glycine arylamidase activity was observed in $B$. fibrisolvens $\mathrm{D} 1^{\mathrm{T}}$ and in a few isolates of $P$. xylanivorans. Similar distribution of enzyme activity was observed in the case of histidine arylamidase; this activity was also observed in one isolate of B. hungatei.

\section{Deoxyribonuclease (DNase) activity}

Nuclease activity (Table 3) was observed in most strains of P. xylanivorans and P. ruminis, and also in some strains of $B$. hungatei. No DNase activity was detected in the culture media of B. fibrisolvens or C. proteoclasticum strains.

\section{Cellular fatty acids}

Cellular fatty acid profiles have been used to establish taxonomic relationships among anaerobic bacteria (Holdeman et al., 1977; Mayberry et al., 1982; Moore et al., 1994) and have also proven to be useful in the classification of anaerobic Gram-negative bacteria (Stoakes et al., 1991). The most extensive work on 21 different Butyrivibrio strains was done by Miyagawa (1982). Moore et al. (1994) determined the fatty acid composition only in B. fibrisolvens $\mathrm{D}^{\mathrm{T}}$ (=ATCC $19171^{\mathrm{T}}$ ). Miyagawa (1982) found that the cellular fatty acid composition varied considerably among strains and divided the Butyrivibrio isolates into two major groups based on fatty acid and fatty aldehyde composition: Group 1 contained branchedchain fatty acids as major components, whereas Group 2 contained only straight-chain fatty acids as major components. Although it is difficult to compare directly our results with those of other authors (different growth media and analyses conditions used), our data (Table 4) in general confirm those of Miyagawa (1982). The fatty acids of P. xylanivorans and B. fibrisolvens contained a low proportion of branched-chain fatty acids and the other three groups of isolates contained the same branched-chain fatty acids as the major ones previously detected by Miyagawa (1982): iso- $\mathrm{C}_{14: 0}$ and anteiso- $\mathrm{C}_{15: 0}$, which are the discriminating fatty acids of $C$. proteoclasticum isolates; iso- $\mathrm{C}_{15: 1}$, a major, characteristic fatty acid of isolates of
Table 4. Cellular fatty acid composition of five species of butyrate-producing bacteria

Species: 1, B. fibrisolvens $(n=2) ; 2$, P. ruminis $(n=8) ; 3, C$. proteoclasticum $(n=7) ; 4, B$. hungatei $(n=8) ; 5$, P. xylanivorans $(n=17)$. Strain numbers of isolates of each species are given in the legend to Table 2. - , Not present or less than $0.5 \%$ of total acids. Mean percentage of the total acids is given for each fatty acid of a set of strains of a species.

\begin{tabular}{|c|c|c|c|c|c|}
\hline Fatty acid & 1 & 2 & 3 & 4 & 5 \\
\hline $\mathrm{C}_{12: 1}$ & - & $1 \cdot 5$ & $1 \cdot 5$ & $1 \cdot 3$ & $1 \cdot 2$ \\
\hline $\mathrm{C}_{12: 0}$ & 0.9 & $1 \cdot 4$ & - & - & - \\
\hline $\mathrm{C}_{13: 1}$ & - & $4 \cdot 0$ & $0 \cdot 8$ & $0 \cdot 5$ & $0 \cdot 8$ \\
\hline iso- $\mathrm{C}_{14: 0}$ & - & $0 \cdot 6$ & $8 \cdot 2$ & $2 \cdot 1$ & - \\
\hline $\mathrm{C}_{14: 0}$ & $2 \cdot 8$ & $14 \cdot 2$ & $3 \cdot 8$ & $2 \cdot 6$ & $3 \cdot 8$ \\
\hline iso- $\mathrm{C}_{13: 0} 3-\mathrm{OH}$ & - & - & $2 \cdot 7$ & $1 \cdot 4$ & - \\
\hline iso- $\mathrm{C}_{15: 1} / \mathrm{C}_{13: 0} 3-\mathrm{OH}^{*}$ & $0 \cdot 7$ & $12 \cdot 7$ & - & $1 \cdot 5$ & $3 \cdot 1$ \\
\hline anteiso- $\mathrm{C}_{15: 1}$ & - & - & $1 \cdot 5$ & $2 \cdot 3$ & - \\
\hline iso- $\mathrm{C}_{15: 0}$ & - & $3 \cdot 0$ & - & - & $0 \cdot 9$ \\
\hline anteiso- $\mathrm{C}_{15: 0}$ & - & $0 \cdot 7$ & $6 \cdot 3$ & $1 \cdot 7$ & - \\
\hline $\mathrm{C}_{15: 1} c 10$ & $1 \cdot 5$ & $2 \cdot 2$ & - & $0 \cdot 9$ & $1 \cdot 8$ \\
\hline $\mathrm{C}_{15: 0}$ & $0 \cdot 8$ & $5 \cdot 5$ & $3 \cdot 1$ & $2 \cdot 7$ & $2 \cdot 2$ \\
\hline iso- $\mathrm{C}_{14: 0} 3-\mathrm{OH}$ & - & $5 \cdot 4$ & - & - & $2 \cdot 4$ \\
\hline $\mathrm{C}_{14: 0} 2-\mathrm{OH}$ & - & - & $15 \cdot 6$ & $4 \cdot 4$ & $1 \cdot 2$ \\
\hline $\mathrm{C}_{14: 0} 3-\mathrm{OH} /$ iso- $\mathrm{C}_{16: 1^{*}}$ & - & $1 \cdot 6$ & $0 \cdot 8$ & $1 \cdot 7$ & - \\
\hline $\mathrm{C}_{16: 1} \subset 9$ & $1 \cdot 2$ & - & - & - & $0 \cdot 7$ \\
\hline iso- $\mathrm{C}_{16: 0}$ & - & - & $16 \cdot 5$ & $15 \cdot 0$ & - \\
\hline $\mathrm{C}_{16: 1}$ & $0 \cdot 6$ & - & - & $12 \cdot 8$ & - \\
\hline $\mathrm{C}_{16: 0}$ & $41 \cdot 3$ & $27 \cdot 6$ & $7 \cdot 8$ & $9 \cdot 1$ & $38 \cdot 2$ \\
\hline $\mathrm{C}_{15: 0} 2-\mathrm{OH}$ & $1 \cdot 7$ & - & $1 \cdot 4$ & - & $3 \cdot 9$ \\
\hline iso- $\mathrm{C}_{17: 1}$ & - & $1 \cdot 0$ & - & $3 \cdot 5$ & $1 \cdot 2$ \\
\hline anteiso- $\mathrm{C}_{17: 1}$ & $7 \cdot 5$ & $5 \cdot 2$ & - & - & $6 \cdot 6$ \\
\hline iso- $\mathrm{C}_{17: 0}$ & $0 \cdot 8$ & - & - & - & $1 \cdot 8$ \\
\hline anteiso- $\mathrm{C}_{17: 0}$ & $3 \cdot 9$ & - & $14 \cdot 6$ & $17 \cdot 2$ & $2 \cdot 6$ \\
\hline $\mathrm{C}_{17: 1}$ & $1 \cdot 3$ & - & - & - & $0 \cdot 7$ \\
\hline $\mathrm{C}_{17: 0}$ & $1 \cdot 6$ & - & - & $1 \cdot 9$ & $2 \cdot 0$ \\
\hline iso- $\mathrm{C}_{16: 0} 3-\mathrm{OH}$ & - & - & - & - & $1 \cdot 0$ \\
\hline $\mathrm{C}_{16: 0} 2-\mathrm{OH}$ & - & - & $2 \cdot 3$ & $6 \cdot 9$ & $1 \cdot 1$ \\
\hline $\mathrm{C}_{16: 0} 3-\mathrm{OH}$ & $0 \cdot 6$ & - & - & - & - \\
\hline iso- $\mathrm{C}_{18: 1}$ & - & - & - & $0 \cdot 9$ & - \\
\hline $\mathrm{C}_{18: 1} c 9$ & $2 \cdot 8$ & - & - & - & - \\
\hline $\mathrm{C}_{18: 1} c 11 / t 9 / t 6$ & $6 \cdot 4$ & - & - & - & - \\
\hline $\mathrm{C}_{18: 1} t 11$ & - & - & - & - & $1 \cdot 1$ \\
\hline $\mathrm{C}_{18: 1}$ & $1 \cdot 3$ & - & - & - & $1 \cdot 4$ \\
\hline $\mathrm{C}_{18: 0}$ & $5 \cdot 7$ & $1 \cdot 2$ & $2 \cdot 0$ & $1 \cdot 5$ & $1 \cdot 6$ \\
\hline iso- $\mathrm{C}_{17: 0} 3-\mathrm{OH}$ & $0 \cdot 7$ & - & - & - & $4 \cdot 0$ \\
\hline $\mathrm{C}_{17: 0} 2-\mathrm{OH}$ & $12 \cdot 7$ & - & - & - & - \\
\hline iso- $\mathrm{C}_{19: 1}$ & $1 \cdot 9$ & $0 \cdot 8$ & $1 \cdot 1$ & $1 \cdot 4$ & $1 \cdot 2$ \\
\hline
\end{tabular}

*The two fatty acids are identified together as one peak by GLC.

P. ruminis; and anteiso- $\mathrm{C}_{17: 0}$, found in C. proteoclasticum, B. hungatei and $B$. fibrisolvens $\mathrm{D}^{\mathrm{T}}$. Our results also confirmed that among straight-chain fatty acids, $\mathrm{C}_{16: 0}$ was generally the major fatty acid in Butyrivibrio and Butyrivibrio-like isolates. The two Pseudobutyrivibrio species 
(P. ruminis and P. xylanivorans) and B. fibrisolvens contained $\mathrm{C}_{16: 0}$ fatty acid in the highest proportion (Van Gylswyk et al., 1996). Other major straight-chain saturated and unsaturated fatty acids detected were $C_{14: 0}, C_{15: 0}$, $\mathrm{C}_{16: 1}$ and $\mathrm{C}_{18: 1}$, which is in total accordance with the results of Miyagawa (1982). The different relative proportions of these fatty acids and the detection of some fatty acids unique to some groups of isolates enabled us to cluster our isolates into five separate species.

There have been many attempts to reclassify Butyrivibriolike isolates (Hungate, 1966; Hespell et al., 1993; Forster et al., 1996). Our data fully support the proposal of two novel bacterial species: the non-proteolytic and nonfibrolytic species $B$. hungatei and the fibrolytic species $P$. xylanivorans. Both species are common in the rumen content of sheep and cow.

\section{Description of Butyrivibrio hungatei sp. nov.}

Butyrivibrio hungatei (hun.ga'te.i.N.L. gen. n. hungatei named after Robert E. Hungate, an American microbiologist, who isolated similar strains in the 1960s).

Cells are Gram-negative, straight to slightly curved rods $(0 \cdot 3-0.5 \times 1.5-2.5 \mu \mathrm{m})$ that do not form endospores. Motile by means of a single polar or subpolar flagellum (Fig. 2). Growth occurs anaerobically at $39^{\circ} \mathrm{C}$, but not at $25^{\circ} \mathrm{C}$. Limited growth is observed at $45^{\circ} \mathrm{C}$. No growth is observed in the presence of oxygen. Arabinose, cellobiose, aesculin, glucose, lactose, maltose, mannose, raffinose, salicin, sucrose and xylose are utilized by the type strain. Tryptophan, urea and gelatin are not utilized. The following substrates do not support growth of the type strain: glycerol; mannitol; melezitose; sorbitol; rhamnose; trehalose. Medium M10 with glucose $(22 \mathrm{mM})$ is fermented to

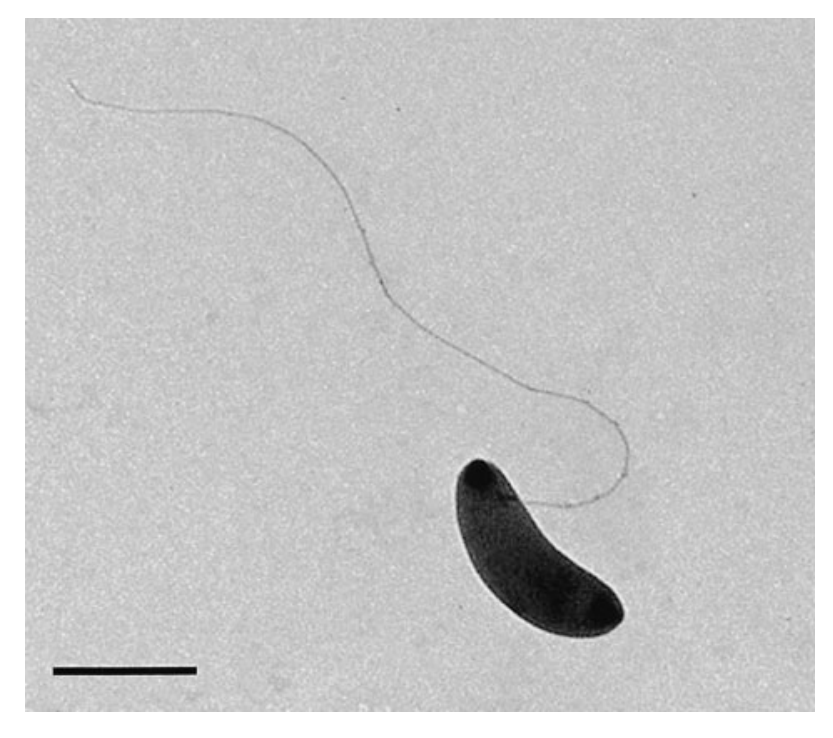

Fig. 2. Electron micrograph of Butyrivibrio hungatei JK $615^{\top}$ cells showing the size and flagellar arrangement. Bar, $1 \mu \mathrm{m}$. formate $(12 \mathrm{mM})$, acetate $(2 \cdot 2 \mathrm{mM})$, butyrate $(10 \cdot 8 \mathrm{mM})$ and ethanol $(3.4 \mathrm{mM})$. No lactate or succinate production is observed. No growth occurs in the absence of fermentable carbohydrates. Does not show any significant fibrolytic or proteolytic activity, utilizing mainly oligo- and monosaccharides as growth substrates. The type strain does not liquefy gelatin, produce hydrogen sulfide, reduce nitrate or hydrolyse urea and is catalase-negative. $\alpha$-Galactosidase, $\alpha$-arabinosidase, phenylalanine arylamidase and leucine arylamidase are produced. No amylase, xylanase, $\beta$-endoglucanase, laminarinase, pectin hydrolase, proteinase or DNase activities are detected. The major cellular fatty acid components of strain JK $615^{\mathrm{T}}$ grown in DSM medium no. 330 without rumen fluid are saturated, branched-chain anteiso- $\mathrm{C}_{17: 0}(17 \cdot 4 \%)$ and iso- $\mathrm{C}_{16: 0}(14 \cdot 5 \%)$, and unsaturated straight-chain $\mathrm{C}_{16: 1}(13 \cdot 2 \%)$ fatty acids. Also present are $\mathrm{C}_{16: 0} 2-\mathrm{OH}(6 \cdot 9 \%), \mathrm{C}_{14: 0} 2-\mathrm{OH}(4 \cdot 3 \%)$ and iso- $\mathrm{C}_{17: 1}(3 \cdot 4 \%)$. Branched-chain fatty acids represent the prevailing proportion of cellular fatty acids in this species. Strains are common isolates in our set of anaerobic rumen bacteria. In the rumen, they participate in the utilization of intermediates of fibre degradation. Strains belonging to Butyrivibrio hungatei are listed in the footnote of Table 3. The type strain is JK $615^{\mathrm{T}}\left(=\mathrm{DSM} 14810^{\mathrm{T}}=\right.$ ATCC BAA $\left.-456^{\mathrm{T}}\right)$. The DNA $\mathrm{G}+\mathrm{C}$ content of the type strain is $44 \cdot 8 \mathrm{~mol} \%$ (as determined by the HPLC method).

\section{Description of Pseudobutyrivibrio xylanivorans sp. nov.}

Pseudobutyrivibrio xylanivorans (xy.la.ni.vo'rans. N.L. n. xylanum xylan; L. part. adj. vorans devouring, digesting; N.L. part. adj. xylanivorans xylan-digesting).

Cells are Gram-negative, straight to slightly curved rods $(0 \cdot 4-0.6 \times 1 \cdot 5-3.0 \mu \mathrm{m})$ that do not form endospores. Cells are motile by means of a single polar or subpolar flagellum (Fig. 3). Growth occurs anaerobically at $39^{\circ} \mathrm{C}$, but not at 25 or $45^{\circ} \mathrm{C}$. No growth is observed in the presence of oxygen. However, exposure of grown liquid culture to air for several hours does not destroy the ability of the species to recover under anaerobic conditions. Substrates that support growth of the type strain are cellobiose, aesculin, glucose, lactose, maltose, mannose, melezitose, salicin, sucrose and xylose. Tryptophan, urea and gelatin are not utilized. The following substrates do not support growth of the type strain: glycerol; mannitol; raffinose; sorbitol; rhamnose; trehalose. Medium M10 with glucose (22 mM) is fermented to formate $(15 \cdot 1 \mathrm{mM})$, butyrate $(17 \cdot 6 \mathrm{mM})$, lactate $(10.9 \mathrm{mM})$, succinate $(0.3 \mathrm{mM})$ and ethanol $(1 \cdot 1 \mathrm{mM})$. Acetate is utilized. No growth occurs in the absence of fermentable carbohydrates. Strain $\mathrm{Mz} 5^{\mathrm{T}}$ does not liquefy gelatin or produce hydrogen sulfide; neither does it reduce nitrate, hydrolyse urea nor produce catalase. It produces $\alpha$-galactosidase, $\alpha$-arabinosidase, xylanase, amylase, $\beta$-endoglucanase, pectin hydrolase, proteinase and DNase. The major cellular fatty acid components of strain $\mathrm{Mz} 5^{\mathrm{T}}$ grown in DSM medium no. 330 without rumen 


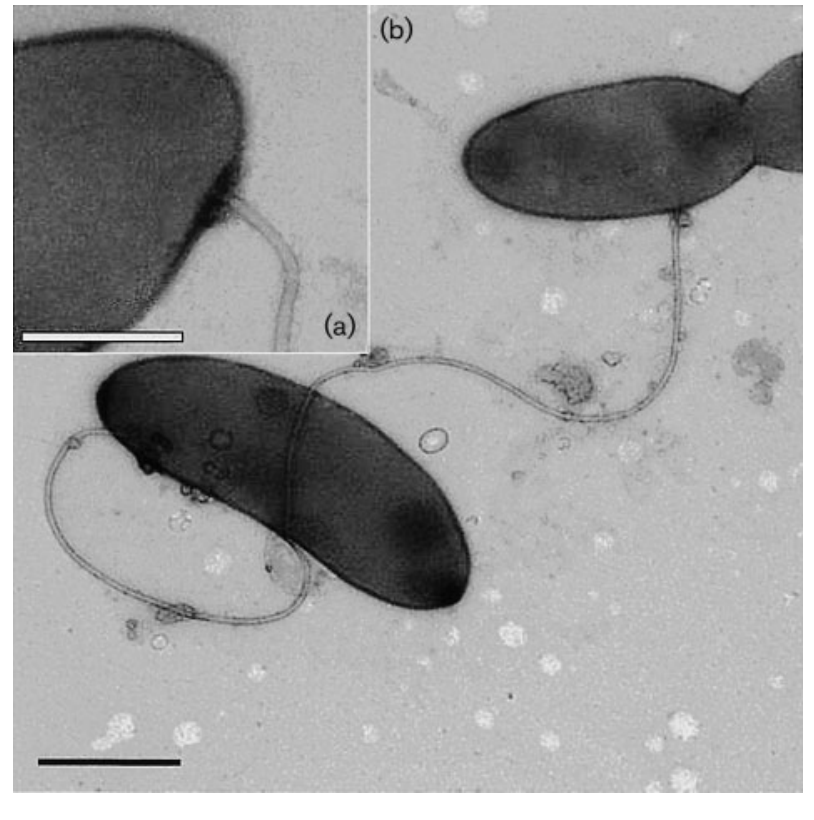

Fig. 3. Electron micrograph of Pseudobutyrivibrio xylanivorans $\mathrm{Mz} 5^{\top}$ cells showing (a) the size and arrangement (bar, $100 \mathrm{~nm}$ ) and (b) flagellar basis (bar, $0.5 \mu \mathrm{m}$ ).

fluid are $\mathrm{C}_{16: 0}(39 \cdot 2 \%)$ and anteiso- $\mathrm{C}_{17: 1}(6 \cdot 4 \%)$, followed by iso- $\mathrm{C}_{17: 0} 3-\mathrm{OH}(3 \cdot 9 \%)$ and $\mathrm{C}_{14: 0}(4 \cdot 3 \%)$. This species is characterized by a higher content of straight-chain cellular fatty acids and a lower content of branchedchain fatty acids. Produces high xylanase activity. Most strains also produce amylase, proteinase and DNase. Laminarinase is detected in some species. Strains belonging to Pseudobutyrivibrio xylanivorans are listed in the footnote of Table 3 . The most common butyrate-producing anaerobic bacterium in our set of bacteria isolated from the rumen of sheep and cow. The type strain is $\mathrm{Mz} 5^{\mathrm{T}}$ $\left(=\mathrm{DSM} 14809^{\mathrm{T}}=\right.$ ATCC BAA $\left.-455^{\mathrm{T}}\right)$. The DNA G $+\mathrm{C}$ content of the type strain is $42 \cdot 1 \mathrm{~mol} \%$ (as determined by the HPLC method).

\section{ACKNOWLEDGEMENTS}

We are most grateful to R. Kostanjšek (University of Ljubljana, Department of Biology, Slovenia) for providing the electron micrographs of the type strains $\mathrm{Mz} 5^{\mathrm{T}}$ and $\mathrm{JK} 615^{\mathrm{T}}$ and to G. Avguštin (University of Ljubljana, Zootechnical Department, Slovenia) for valuable discussions. This work was funded by The Grant Agency of the Czech Republic (Project No. 524/99/0602) and also supported by The Ministry of Education, Science and Sports of the Republic of Slovenia.

\section{REFERENCES}

Attwood, G. T. \& Reilly, K. (1995). Identification of proteolytic rumen bacteria isolated from New Zealand cattle. J Appl Bacteriol 79, $22-29$.
Attwood, G. T., Reilly, K. \& Patel, B. K. C. (1996). Clostridium proteoclasticum sp. nov., a novel proteolytic bacterium from the bovine rumen. Int J Syst Bacteriol 46, 753-758.

Avguštin, G., Wallace, R. J. \& Flint, H. J. (1997). Phylogenetic diversity among ruminal isolates of Prevotella ruminicola: proposal of Prevotella brevis sp. nov., Prevotella bryantii sp. nov., and Prevotella albensis sp. nov. and redefinition of Prevotella ruminicola. Int J Syst Bacteriol 47, 284-288.

Barcenilla, A., Pryde, S. E., Martin, J. C., Duncan, S. H., Stewart, C. S., Henderson, C. \& Flint, H. J. (2000). Phylogenetic relationships of butyrate-producing bacteria from the human gut. Appl Environ Microbiol 66, 1654-1661.

Collins, M. D., Lawson, P. A., Willems, A., Cordoba, J. J., FernandezGarayzabal, J., Garcia, P., Cai, J., Hippe, H. \& Farrow, J. A. E. (1994). The phylogeny of the genus Clostridium: proposal of five new genera and eleven new species combinations. Int J Syst Bacteriol 44, 812-826.

Diez-Gonzalez, F., Bond, D. R., Jennings, E. \& Russell, J. B. (1999). Alternative schemes of butyrate production in Butyrivibrio fibrisolvens and their relationship to acetate utilization, lactate production and phylogeny. Arch Microbiol 171, 324-330.

Felsenstein, J. (1985). Confidence limits on phylogenies: an approach using the bootstrap. Evolution 39, 783-791.

Felsenstein, J. (1989). PHYLIP - Phylogeny inference package (version 3.2). Cladistics 5, 164-166.

Forster, R. J., Teather, R. M., Gong, J. \& Deng, S. J. (1996). $16 \mathrm{~S}$ rDNA analysis of Butyrivibrio fibrisolvens: phylogenetic position and relation to butyrate-producing anaerobic bacteria from the rumen of white-tailed deer. Lett Appl Microbiol 23, 218-222.

Forster, R. J., Gong, J. \& Teather, R. M. (1997). Group-specific $16 \mathrm{~S}$ rRNA hybridization probes for determinative and community structure studies of Butyrivibrio fibrisolvens in the rumen. Appl Environ Microbiol 63, 1256-1260.

Gregg, K., Cooper, C. L., Schafer, D. J., Sharpe, H., Beard, C. E., Allen, G. \& Xu, J. (1994). Detoxification of the plant toxin fluoroacetate by a genetically modified rumen bacterium. Biotechnology 12, 1361-1365.

Hall, T. A. (1999). BIOEDIT: a user-friendly biological sequence alignment editor and analysis program for Windows 95/98/NT. Nucleic Acids Symp Ser 41, 95-98.

Hazlewood, G. P., Theodorou, M. K., Hutchings, A., Jordan, D. J. \& Galfre, G. (1986). Preparation and characterization of monoclonal antibodies to a Butyrivibrio sp. and their potential use in the identification of rumen butyrivibrios, using enzyme-linked immunosorbent assay. J Gen Microbiol 132, 43-52.

Hespell, R. B., Kato, K. \& Costerton, J. W. (1993). Characterization of the cell wall of Butyrivibrio species. Can J Microbiol 39, 912-921.

Holdeman, L. V., Cato, E. P. \& Moore, W. E. C. (1977). Anaerobe Laboratory Manual, 4th edn. Blacksburg, VA: Virginia Polytechnic Institute and State University.

Hudman, J. F. \& Gregg, K. (1989). Genetic diversity among strains of bacteria from the rumen. Curr Microbiol 19, 313-318.

Hungate, E. R. (1966). The Rumen and its Microbes. New York: Academic Press.

Kimura, M. (1980). A simple method for estimating evolutionary rates of base substitutions through comparative studies of nucleotide sequences. J Mol Evol 16, 111-120.

Kopečný, J. \& Bartoš, S. (1990). Activity of hydrolases in the gastrointestinal tract of goats. Small Rumin Res 3, 25-35.

Kopečný, J., Marinšek-Logar, R. \& Kobayashi, Y. (2001). Phenotypic and genetic data supporting reclassification of Butyrivibrio fibrisolvens isolates. Folia Microbiol 46, 45-48. 
McAllister, T. A., Cheng, K. J., Rode, L. M. \& Forsberg, C. W. (1990). Digestion of barley, maize and wheat by selected species of ruminal bacteria. Appl Environ Microbiol 56, 46-53.

Maidak, B. L., Larsen, N., McCaughey, M. J., Overbeek, R., Olsen, G. J., Foge, K., Blandy, J. \& Woese, C. R. (1994). The ribosomal database project. Nucleic Acids Res 22, 3485-3487.

Mannarelli, B. M., Stack, R. J., Lee, D. \& Ericsson, L. (1990). Taxonomic relatedness of Butyrivibrio, Lachnospira, Roseburia, and Eubacterium species as determined by DNA hybridization and extracellular-polysaccharide analysis. Int J Syst Bacteriol 40, 370-378.

Margherita, S. S., Hungate, R. E. \& Storz, H. (1964). Variation in rumen Butyrivibrio strains. J Bacteriol 87, 1304-1308.

Mayberry, W. R., Lambe, D. W., Jr \& Ferguson, K. P. (1982). Identification of Bacteroides species by cellular fatty acid profiles. Int J Syst Bacteriol 32, 21-27.

Mesbah, M., Premachandran, U. \& Whitman, W. B. (1989). Precise measurement of the $\mathrm{G}+\mathrm{C}$ content of deoxyribonucleic acid by highperformance liquid chromatography. Int J Syst Bacteriol 39, 159-167.

Miyagawa, E. (1982). Cellular fatty acid and fatty aldehyde composition of rumen bacteria. J Gen Appl Microbiol 28, 389-408.

Moore, L. V. H., Bourne, D. M. \& Moore, W. E. C. (1994). Comparative distribution and taxonomic value of cellular fatty acids in thirty-three genera of anaerobic Gram-negative bacilli. Int J Syst Bacteriol 44, 338-347.

Moore, W. E. C., Johnson, J. L. \& Holdeman, L. V. (1976). Emendation of Bacteriodaceae and Butyrivibrio and description of Desulfomonas gen. nov. and ten new species in the genera Desulfomonas, Butyrivibrio, Eubacterium, Clostridium, and Ruminococcus. Int J Syst Bacteriol 26, 238-252.

Mrázek, J. \& Kopečný, J. (2001). Development of competitive PCR for detection of Butyrivibrio fibrisolvens in the rumen. Folia Microbiol 46, 63-65.

Robards, A. W. \& Wilson, A. J. (1993). Procedures in Electron Microscopy. New York: John Wiley.

Roche, C., Albertyn, H., Van Gylswyk, N. O. \& Kistner, A. (1973). The growth response of cellulolytic acetate-utilizing and acetateproducing butyrivibrios to volatile fatty acids and other nutrients. J Gen Microbiol 78, 253-260.
Saitou, N. \& Nei, M. (1987). The neighbor-joining method: a new method for reconstructing phylogenetic trees. Mol Biol Evol 4, 406425.

Sambrook, J., Fritsch, E. F. \& Maniatis, T. (1989). Molecular Cloning: a Laboratory Manual, 2nd edn. Cold Spring Harbor, NY: Cold Spring Harbor Laboratory.

Stack, R. J. (1988). Neutral sugar composition of extracellular polysaccharides produced by strains of Butyrivibrio fibrisolvens. Appl Environ Microbiol 54, 878-883.

Stewart, C. S., Flint, H. J. \& Bryant, M. P. (1997). The rumen bacteria. In The Rumen Microbial Ecosystem, pp. 35-38. Edited by P. N. Hobson \& C. S. Stewart. London: Blackie Academic \& Professional.

Stoakes, L., Kelly, T., Schieven, B., Harley, D., Ramos, M., Lannigan, R., Groves, D. \& Hussain, Z. (1991). Gas-liquid chromatographic analysis of cellular fatty acids for identification of Gram-negative anaerobic bacilli. J Clin Microbiol 29, 2636-2638.

Tajima, K., Aminov, R. I., Nagamine, T., Ogata, K., Nakamura, M., Matsui, H. \& Benno, Y. (1999). Rumen bacterial diversity as determined by sequence analysis of $16 \mathrm{~S}$ rDNA libraries. FEMS Microbiol Ecol 29, 159-169.

Thompson, J. D., Higgins, D. G. \& Gibson, T. J. (1994). CLUSTAL W: improving the sensitivity of progressive multiple sequence alignment through sequence weighting, position-specific gap penalties and weight matrix choice. Nucleic Acids Res 22, 4673-4680.

Van der Toorn, J. J. K. T. \& Van Gylswyk, N. O. (1985). Xylandigesting bacteria from the rumen of sheep fed maize straw diets. J Gen Microbiol 131, 2601-2607.

Van Gylswyk, N. O., Hippe, H. \& Rainey, F. A. (1996). Pseudobutyrivibrio ruminis gen. nov., sp. nov., a butyrate-producing bacterium from the rumen that closely resembles Butyrivibrio fibrisolvens in phenotype. Int J Syst Bacteriol 46, 559-563.

Weisburg, W. G., Barns, S. M., Pelletier, D. A. \& Lane, D. J. (1991). $16 \mathrm{~S}$ ribosomal DNA amplification for phylogenetic study. J Bacteriol 173, 697-703.

Willems, A., Amat-Marco, M. \& Collins, M. D. (1996). Phylogenetic analysis of Butyrivibrio strains reveals three distinct groups of species within the Clostridium subphylum of the Gram-positive bacteria. Int J Syst Bacteriol 46, 195-199. 